\title{
El uso expresivo de los posesivos en tres dialectos venezolanos.
}

\author{
The expressive use of possessives in three Venezuelan dialects.
}

DOI: $10.32870 /$ sincronia.axxv.n79.32a21

\author{
Krístel Guirado \\ Universidad Central de Venezuela/Universidad de Zaragoza (VENEZUELA) \\ CE: kristelguirado@gmail.com / ID ORCID: 0000-0002-7933-2758
}

\section{Esta obra está bajo una Licencia Creative Commons Atribución-NoComercial 4.0 Internacional}

Recibido: $25 / 09 / 2020$

Revisado: $18 / 10 / 2020$

Aprobado: 06/11/2020

\section{RESUMEN}

En esta investigación, analizo cinco usos del posesivo de $1^{\text {a }}$ sg., propios del español hablado en Venezuela: alternancia en contexto nominal (mi casa la casa mía), en contexto adverbial (delante de mí mío), en contexto verbal (se burla de mí mío, una casa hecha mía por mí), posesivo redundante (mi casa mía) y ponderativo (me compró mi casa). Estudio los casos en los dialectos de tres ciudades (Caracas, Maracaibo, Mérida) y presento la investigación en dos partes; en la primera, analizo estadísticamente el posesivo en contexto nominal (efectos mixtos y árboles de inferencia condicional) para determinar si las formas están condicionadas por factores lingüísticos y sociales; en la segunda, describo los otros casos -menos abundantes en la muestra- para precisar su ocurrencia y establecer el carácter expresivo de su empleo pragmático. Los resultados muestran que: i. las relaciones semánticas de convivencia social y autorrealización, la función de atributo y los hablantes adultos de nivel bajo favorecen el uso del posesivo posnominal tónico; ii. en contraste, los posesivos enfáticos (posadverbial, apreciativo, ponderativo y redundante,) son más comunes en los jóvenes caraqueños y su uso resulta ser una estrategia efectiva para dar realce expresivo al enunciado.

Palabras Clave: Posesivo de $1^{\text {a }}$ sg. Variación dialectal. Modelo de efectos mixtos. Arboles de inferencia condicional. Intensificación. Realce expresivo.

\section{ABSTRACT}

In this research, I analyze five use of the first-person singular possessive, typical of Spanish spoken in Venezuela: alternation in nominal context ( $\mathbf{m i}$ casa $\sim$ la casa mía), alternation in adverbial context

\footnotetext{
* Agradezco a Matti Marttinen y a Miriam Bouzouita por sus oportunas y pertinentes observaciones. Huelga decir que todos los errores que permanezcan en esta contribución son enteramente de mi responsabilidad.
} 
(delante de mí mío), alternation in verbal context (se burla de mímío, una casa hecha mía por mí), redundant possessive (mi casa mía) and ponderative possessive (me compró mi casa). I study the cases in the dialects of three cities (Caracas, Maracaibo, Mérida) and I present the results in two parts; in the first, I statistically analyze the possessive in nominal context (mixed effects and conditional trees) to determine if the forms are conditioned by linguistic and social factors; in the second, I describe the other cases -less abundant in the sample- to specify their occurrence and establish the expressive character of their pragmatic use. The results show that: i. the semantic relationships of social coexistence and self-realization, the attribute function, and low-level adult speakers favor the use of the postnominal stressed forms; ii. in contrast, emphatic possessives (postadverbial, appreciative, ponderative, and redundant) are more common in young Caracas speakers and their use constitutes an effective strategy to give expressive enhancement to the statement.

Keywords: First-person singular possessive. Dialectal variation. Mixed effects model. Conditional inference trees. Intensification. Expressive enhancement.

\section{Introducción: la expresión de posesión en español}

En español, la noción de 'posesión' puede expresarse con el uso de un adjetivo determinativo átono antepuesto (mi - su - nuestra ... casa), de uno tónico pospuesto (la casa mía - suya - nuestra), o con una construcción perifrástica conocida como posesivo analítico (la casa de Rosa - de mi mamá). El antepuesto y el analítico son los usos más frecuentes, mientras que el pospuesto se reserva para marcar énfasis y contraste (Picallo \& Rigau, 1999; Real Academia Española \& Asociación de Academias de la Lengua Española, ss. RAE \& ASALE, 2009). ${ }^{1}$

Picallo y Rigau $(1999, \S 15.2 .4)$ también advierten que algunos empleos del antepuesto se usan "para intensificar o alterar una característica que se asume como supuesta o inherente". La intensificación puede ratificar la característica (Me tomé mi café y mi tostada de todos los días), señalar su carácter inesperado (Estos adornos tienen su gracia) o reforzar un atributo (Esta institución tiene ya sus dos siglos de existencia). ${ }^{2}$

Otro uso diferenciado por la tradición gramatical es el denominado posesivo doblado o duplicado, doble o redundante, construcciones que "repiten la información correspondiente al poseedor dentro del grupo nominal" (RAE \& ASALE, 2009, §18.4f). Se distinguen dos variantes, con

\footnotetext{
${ }^{1}$ Esta interpretación ha sido señalada previamente, entre otros, por Radelli (1978) y Porto Dapena (1982).

2 Porto Dapena (1982), Satorre (1999), entre otros, también mencionan la cualidad enfática del posesivo antepuesto.
} 
posesivo átono antepuesto al analítico ( $m i$ casa de mí) y con tónico pospuesto (mi casa mía). La Nueva gramática de la lengua española (ss. NGLE) califica estas construcciones de "impropias del español general", aunque no son ajenas al desarrollo de la lengua, pues se documentan en el castellano medieval y clásico. Su empleo actual es frecuente en algunas regiones andinas y centroamericanas; y en el español europeo, se restringe a la segunda persona de cortesía en el habla popular. ${ }^{3}$

Respecto al uso del posesivo con adverbios locativos, la NGLE reporta tres pautas: analítico (detrás de mí), pospuesto masculino (detrás mío) y femenino (detrás mía), pero expresa su preferencia por la primera, ya que los pospuestos pierden prestigio en registros menos populares. ${ }^{4}$ Aunque Picallo y Rigau $(1999, \S 15.3 .1)$ lo identifican como un uso propio "del habla coloquial o dialectal en el español peninsular", "muy común en el español de América", 5 su empleo es motivo de preocupación y opiniones normativas. ${ }^{6}$

En consecuencia, el objetivo de la presente investigación consiste en estudiar cinco fenómenos asociados al uso de los posesivos de 1a sg., presentes en el español hablado en Venezuela: i. alternancia en contexto nominal: mi casa la casa mía; ii. alternancia en contexto adverbial: delante de mí mío; iii. alternancia en contexto verbal (apreciativo): una casa hecha mía de/por mí; iv. uso enfático redundante: mi casa mía; y, v. uso enfático ponderativo: me compró mi casa.

Los fenómenos se analizan en tres ciudades (Caracas, Mérida y Maracaibo), ubicadas en diferentes áreas dialectales del país (central, andina y zuliana), para determinar -cuando la

\footnotetext{
${ }^{3}$ Sobre esta estructura, cf. Granda $(1966,1997)$, Lapesa (1971) y la abundante contribución de Concepción Company Company -disponible en: http://www.concepcioncompany.com/.

${ }^{4}$ La alternancia se da con otras partículas discursivas prepositivas o adverbiales: en mi lugar ${ }^{\sim}$ en lugar de mí/mío; de mi parte de parte mía; a mi pesar a pesar de mí/mío (cf. Picallo \& Rigau, 1999).

${ }^{5}$ Desde inicios del siglo XX, estos usos han sido documentados en las hablas peninsulares y americanas por diversos estudios dialectológicos. Trabajos recientes confirman su extensión: Aleza (2010); Bertolotti (2014); Santana (2014); Eddington (2017); Salgado y Bouzouita (2017); Marttinen y Bouzouita (2018); Bouzouita, Castillo y Pato (2018).

${ }^{6}$ Por ejemplo, la web del Centro Virtual Cervantes aloja el espacio Al habla. Museo de los horrores. En ese "terrorífico Museo" figuran dos fenómenos: el uso de posesivos con adverbios y el uso superfluo para referirse a la posesión inalienable. Asimismo, todas las entradas de los adverbios locativos del Diccionario Panhispánico de Dudas incluyen la coletilla: "no se considera correcto su uso con posesivos" (RAE \& ASALE, 2005).
} 
frecuencia lo permita- si las formas están condicionadas lingüística, social y/o dialectalmente y establecer la naturaleza pragmática de su empleo.

He centrado mi atención en el estudio de la 1a persona porque es la más frecuente en el habla (Silva-Corvalán \& Enrique-Arias, 2017) y su paradigma presenta una menor ambigüedad morfológica y referencial: solo registra la forma prenominal ( $m i, m i s$, sin variación de género) y la acopada posnominal (mía-o-s); esta última no alterna con el grupo preposicional de + PRON ( ${ }^{*} / a$ casa de yo/mí); ambas designan un solo poseedor y tienen referente no ambiguo (el hablante), presente en el contexto discursivo, con una mayor animacidad, concreción y perspectiva. La implicación de la individualidad del hablante contrapone la 1a $\mathrm{sg}$. a las otras del paradigma. En virtud de que la intención última de esta investigación es señalar que los usos marcados son expresión de la subjetividad del hablante, la 1a sg. constituye la máxima expresión de esta. ${ }^{7}$

\section{El uso de los posesivos de 1a sg. en el español de Venezuela}

\subsection{Descripciones generales}

Ledezma y Obregón (1990) advierten que, en el habla informal, el posesivo pospuesto al grupo nominal es más frecuente que las formas apocopadas. Ledezma y Barrera (1985), Ledezma y Obregón (1990) y Bentivoglio y Sedano (1992) también mencionan el uso de posesivos pospuesto con adverbios de lugar (detrás mío). Bentivoglio y Sedano $(1998$, p.127) asocian este empleo al carácter afectivo de la expresión:

Cuando un caraqueño habla de algo que le pertenece, puede decir la mamá mía, los hijos míos, el primo tuyo en lugar de decir mi mamá, mis hijos y tu primo. Parece que el uso del adjetivo posesivo después del sustantivo sirve para que el hablante exprese un vínculo más afectivo con la persona a la que hace referencia, vínculo que, por supuesto, puede extenderse también a seres u objetos igualmente queridos y apreciados, pero no humanos, como la perrita mía, el perico mío, el carrito mío.

\footnotetext{
${ }^{7}$ Como dice poéticamente Solkoff (2002, p. 215): “Allí donde la Tercera persona transita una arquitectura paradigmática de enunciados prolijamente simétricos y escapa de los callejones intencionales de la subjetividad, la Primera persona enhebra con hilos mentalistas una trama singular, desafiando recorridos inaccesibles, proclamando su autoridad en un lenguaje misterioso".
} 
En cuanto al falso antepuesto, Ledezma y Barrera (1990) registran su uso en el habla informal (no se moleste, mi doñita; me pongo mis tacones; aliñé mi arroz). En cambio, consideran que el posesivo redundante no es habitual, aunque documentan algunos casos (contesta toda mi tripulación mía; aprendí a pintar por mi cuenta mía).

Finalmente, he denominado apreciativo el uso del posesivo tónico para sustituir un complemento de régimen -fijo u opcional- encabezado por las preposiciones por: esos cuadros son pintados míos por mí; esta casita sí es hecha mía por mí (Ledezma \& Barrera, 1985) y de: estás enamorao mío de mí; se burla mío de mí (Guirado, 2012).

\subsection{Estudios empíricos}

\subsubsection{Posesivo en contexto nominal}

De Stefano y Chumaceiro (1992) analizan los posesivos de 1a sg. en grupos nominales en la ciudad de Caracas. El uso más frecuente fue el antepuesto. Los usos pospuestos se asociaron a sustantivos que denotan familiaridad (hijo, novio, amigo, etc.) y a las frases predicativas (Ese es hijo mío). Las autoras también encontraron correlación con los hablantes entre 30 y 45 años, del nivel socioeconómico bajo. Al final, señalan que los usos pospuestos "comunican también contenidos afectivos y valores estilísticos" (p. 826).

De Stefano (1996), además, analiza estos posesivos en el habla de Maracaibo. En esta variedad, el uso pospuesto tampoco fue abundante y se asoció a hombres mayores de 60 años, igualmente, de los niveles más bajos. La autora advierte que el empleo de sustantivos de familiaridad con ambos posesivos fue similar, lo que desmentiría empíricamente la relación entre la posposición y este tipo de sustantivos.

Lo Ponte (2016) identifica e ilustra el uso pospuesto de 1a sg. en la entrevista de un joven procedente de un barrio pobre de Caracas, con bajo nivel de instrucción, privado de libertad en una cárcel de Caracas: "Y si me contratan 'pa- que mate a un amigo mío, voy y le digo al amigo mío y voy con el amigo mío y lo mato a él". (p. 69). 


\subsubsection{Posesivo posadverbial}

De Stefano y Chumaceiro (1992) revisan la posposición del posesivo al adverbio (debajo mío, delante mío, al lado mío 'junto'), pero esta resultó escasa en la oralidad caraqueña. Navarro (2001) también estudia la alternancia en el habla de Valencia, y solo documenta dos casos en hablantes de estrato social bajo (yo sentía el viejo encima mío; Tengo unos primos que viven al frente mío). Murguey (2010, p.65), en cambio, documenta "[o]currencias abundantes de formas plenas de los posesivos pospuestos" en una muestra de diversas ciudades venezolanas (Caracas, Mérida, Margarita y Porlamar).

\subsubsection{Posesivo antepuesto enfático}

Finalmente, Ugueto (2015) realiza un estudio de casos de los posesivos átonos antepuestos (mi-tusu) cuando modifican frases que designan objetos o cualidades físicas o psicológicas, en seis entrevistas del habla actual de Caracas. Una proporción importante de casos de 1a sg. (27\%) corresponden a "posesivos expresivos" (parte de mi francés que sé lo sé por... por mis lecturas; me echo mi agua y mi jabón otra vez). Sobre la motivación pragmática del uso (énfasis), la autora señala: "se puede percibir auditivamente una diferencia fónica suprasegmental entre la pronunciación de las FNs en las que el posesivo expresa un matiz emotivo-expresivo" (p. 100).

\section{Corpus y selección de casos}

La muestra está constituida por 144 grabaciones del Corpus dialectal para el estudio sociolingüístico del español hablado en Venezuela a finales del siglo XX (Cf. Guirado, 2021). El CORDIA-VEN-sXX es un subcorpus, producto de la reingeniería de tres corpus del proyecto GREHV (Cf. Bentivoglio, 1996), creado con el propósito de hacer analisis en una microdiacronía del siglo XX. ${ }^{8}$ Las entrevistas están distribuidas equitativamente en tres dialectos: Maracaibo, Caracas y Mérida; cuatro grupos etarios: 14 a 29 años, 30 a 45, 46 a 60 y de 61 o más años; tres niveles socioeconómicos: alto, medio y bajo; y sexo: hombres y mujeres. En la tabla 1 se puede observar la distribución:

\footnotetext{
${ }^{8}$ Cf. Guirado (2015) sobre la noción de reingeniería de corpus, y cf. Pons Bordería (2014) sobre la de microdiacronía.
} 
Tabla 1. CORDIA-VEN-sXX

\begin{tabular}{|c|c|c|c|c|c|c|c|c|c|c|}
\hline \multirow[b]{2}{*}{ CIUDAD } & \multirow{2}{*}{$\begin{array}{r}\text { GE } \\
\text { NS/SEX }\end{array}$} & \multicolumn{2}{|c|}{$14-29$ años } & \multicolumn{2}{|c|}{$30-45$ años } & \multicolumn{2}{|c|}{$46-60$ años } & \multicolumn{2}{|c|}{61 años o + } & \multirow{2}{*}{ Total } \\
\hline & & $h$ & $m$ & $h$ & $m$ & $h$ & $m$ & $h$ & $m$ & \\
\hline \multirow{3}{*}{$\begin{array}{c}\text { MARACAIBO } \\
1986\end{array}$} & alto & 2 & 2 & 2 & 2 & 2 & 2 & 2 & 2 & 16 \\
\hline & medio & 2 & 2 & 2 & 2 & 2 & 2 & 2 & 2 & 1648 \\
\hline & bajo & 2 & 2 & 2 & 2 & 2 & 2 & 2 & 2 & 16 \\
\hline \multirow{3}{*}{$\begin{array}{c}\text { CARACAS } \\
1987\end{array}$} & alto & 2 & 2 & 2 & 2 & 2 & 2 & 2 & 2 & 16 \\
\hline & medio & 2 & 2 & 2 & 2 & 2 & 2 & 2 & 2 & 1648 \\
\hline & bajo & 2 & 2 & 2 & 2 & 2 & 2 & 2 & 2 & 16 \\
\hline \multirow{3}{*}{$\begin{array}{c}\text { MÉRIDA } \\
1995\end{array}$} & alto & 2 & 2 & 2 & 2 & 2 & 2 & 2 & 2 & 16 \\
\hline & medio & 2 & 2 & 2 & 2 & 2 & 2 & 2 & 2 & 1648 \\
\hline & bajo & 2 & 2 & 2 & 2 & 2 & 2 & 2 & 2 & 16 \\
\hline
\end{tabular}

Fuente: (Guirado, 2021, p. 65)

Extraje del corpus todas las cláusulas declarativas en las cuales aparecen formas posesivas de $1^{\text {a }} \mathrm{sg}$. (mi-s, mía-o-s, de/por mí) en contextos de modificación nominal, adverbial y verbal. Eliminé del análisis los usos pronominales (esas palabras eran/parecen mías, los [hijos] míos están grandes) y las repeticiones, hesitaciones y otras correcciones propias del texto oral.

Tampoco tomé en cuenta el empleo de posesivos en interjecciones (iDios mío!) y vocativos (mi amor, mi vida, mija, hijo de mi alma, hijo mío, querida mía), ni su uso invariable en dichos (Dejé mi granito de arena), títulos (“Mi libro primario"), citas de canciones ("Cabrito salí de mi huerta, señor que no tengo puerta") y el uso enfático del sintagma mi persona en lugar de los pronombres yo, mí, me (llegamos ella y mi persona, se acuerda de mi persona, atacaron a mi persona).

Finalmente, reservé las partículas que funcionan como marcadores de expresión de punto de vista (a mi manera/modo de ver, a mi juicio, en mi concepto, en mi opinión), y otras expresiones lexicalizadas (a mi vista/alcance 'frente a mí', en mi cara 'frente a mí', por mi cuenta 'a mi juicio, sin contar con otros', en mi vida 'jamás/nunca', toda mi vida 'siempre', [no] ser mentira/invento mía-o, ser cosa mía, para un estudio posterior).

\section{Análisis y discusión}

Los resultados de la investigación se presentan y discuten en dos partes. En la primera (§4.1), se hace un análisis estadístico (distribución y análisis inferencial) de la alternancia del posesivo en 
contexto nominal. En la segunda (§4.2), se describen los otros usos, menos frecuentes en el corpus (posadverbial, apreciativo, redundante y ponderativo).

\subsection{Primera parte: alternancia del posesivo en contexto nominal}

\subsubsection{Variables estudiadas y distribución general ${ }^{9}$}

La variable dependiente del estudio consta de dos variantes, la forma antepuesta (1) y la pospuesta (2) del posesivo de 1a sg. a un grupo nominal:
(1) / Posesivo adjetival de 1aㅗ sg. antepuesto /
a. ya mi piel no está para esos menesteres (MB-B3FA) ${ }^{10}$
b. mi papá era ministro para esa época (CA-A1MB)
c. tengo mis discos... me compré discos de ACDC (MD-A1MA)

\section{(2) / Posesivo adjetival de 1a sg. pospuesto /}

a. los amigos míos patinaban y se... se pegaban de la parrilla (MB-B3MB)

b. la niñez mía fue muy bella (CA-C5MB)

c. el nombramiento mío es de aseador en la Universidad (MD-C5MA)

El total de casos analizados fue de 3663 , de los cuales la mayoría corresponde a formas antepuestas (92\%, n: 3375). En la tabla 2 se muestran las frecuencias de uso:

Tabla 2. Anteposición posposición del posesivo de 1aㅗ sg. en el CORDIA-VEN-sXX

\begin{tabular}{ccc}
\hline POSPOSICIÓN & ANTEPOSICIÓN & TOtal \\
\hline $288(8 \%)$ & $3375(92 \%)$ & 3663 \\
\hline
\end{tabular}

Fuente: Elaboración propia

\footnotetext{
${ }^{9}$ Además de los descritos en $\S 3$, también descarté los casos del posesivo pospuesto cuando es obligatorio, ya que la alternancia no se documenta en el español de Venezuela. A saber: con artículo indeterminado (unas/otras/seis amigas mías); con demostrativo (esta amiga mía); como argumento de haber (hay amigos míos); o con cuantificador (era muy amigo mío), salvo casos con el cuantificador flotante todo-a-s, el cual permite la alternancia.

${ }^{10} \mathrm{El}$ código al final de los ejemplos describe la estratificación del hablante: i. ciudad: $M B, C A, M D=$ Maracaibo, Caracas, Mérida; ii. grupo etario: A, B, C, D = 14-29/30-45/46-60/61 o más años; iii. nivel socioeconómico: 1, 3, 5 = alto, medio, bajo; iv. sexo: $\mathrm{M}, \mathrm{F}=$ hombre, mujer; $v$. identificación de cada hablante dentro de la casilla: $\mathrm{A}, \mathrm{B}$.
} 
A continuación, se desglosan los casos analizados por dialecto y se comparan con las frecuencias registradas en otras cuatro ciudades americanas:

Tabla 3. Distribución del posesivo posnominal de $1^{\text {a }}$ sg. en varias ciudades americanas

\begin{tabular}{|c|c|c|c|c|c|c|c|}
\hline INVESTIGACIÓN & Ciudad & Año grab & Po & & AN & & Total \\
\hline De Stefano y Chumaceiro (1992) & Caracas, Ven & 1977 & 89 & $13 \%$ & 614 & $87 \%$ & 703 \\
\hline Sánche & San José, C. Rica & 1984 & 28 & $13 \%$ & 174 & $87 \%$ & 202 \\
\hline$\rightarrow \mathrm{Gu}$ & & $\begin{array}{l}1986 \\
1987 \\
1995\end{array}$ & $\begin{array}{r}86 \\
105 \\
97\end{array}$ & $\begin{array}{r}9 \% \\
6 \% \\
12 \%\end{array}$ & $\begin{array}{r}861 \\
1796 \\
718\end{array}$ & $\begin{array}{l}91 \% \\
94 \% \\
88 \%\end{array}$ & $\begin{array}{r}947 \\
1901\end{array}$ \\
\hline rozo & illa, col & $1997-$ & 32 & $7 \%$ & 430 & $93 \%$ & 462 \\
\hline Pach & na, cub & $1998-\mathrm{c}$ & 5 & $5 \%$ & 86 & $95 \%$ & 91 \\
\hline Freeman (2019) & Medellín, Col & 2007-09 & 49 & $8 \%$ & 576 & $92 \%$ & 62 \\
\hline
\end{tabular}

(Sánchez, 2008); (Orozco, 2210); (Pacheco y Bouzouita, 2017); (Freeman, 2019)

Fuente: Elaboración propia

En la tabla 3 se aprecia que la forma antepuesta es la más frecuente en el habla de las siete ciudades. La tendencia más alta de posesivo posnominal se registra en las grabaciones de Caracas de 1977 (13\%), San José de Costa Rica (13\%) y Mérida (12\%).

Ya que mi interés se centra en describir la forma marcada del posesivo, he procurado compensar la insuficiencia de los casos posnominales con una serie de ajustes en los datos. El primero consiste en excluir las entrevistas en las que solo se emplea una de las formas del posesivo, con el propósito de disminuir la desagregación de datos por hablante y garantizar el mayor equilibrio posible en los contextos.

En consecuencia, el total de hablantes que alternan ambas formas se restringió a 99 (49 mujeres y 50 hombres), distribuidos de manera relativamente proporcional en las tres ciudades (32 en Maracaibo, 33 en Caracas y 34 en Mérida) y los tres niveles (alto: 30, medio: 30, bajo: 39). Sin embargo, los grupos etarios presentan una parcial proporcionalidad, ya que los jóvenes son bastante menos (jóvenes: 17, adultos: 29, adultos plenos: 27, adultos mayores: 26). Al depurar la muestra, el total de ocurrencias se redujo a 2666. Posteriormente, diseñé un modelo de seis variables independientes, dos lingüísticas: i. relación semántica; y, ii. función sintáctica; y cuatro extralingüísticas: i. grupo etario; ii. nivel socioeconómico; iii. sexo; y, iv. ciudad. 


\subsubsection{El posesivo posnominal y la relación semántica}

Para el análisis de la variable relación semántica denotada por el sustantivo al que determina el posesivo, diferencié las entidades en más o menos humanas y, luego, las categoricé según propiedades más específicas del sustantivo modificado. En la tabla 4, se ofrecen los porcentajes de uso, calculados en la nueva distribución de casos:

Tabla 4. Porcentaje del posesivo posnominal de 1 a sg. con entidades [+ HUM] y [- HUM]

\begin{tabular}{|c|c|c|c|c|c|c|c|c|}
\hline$\%$ & [+HUM] & Pos & $n$ & & [-HUM] & Pos & $n$ & $\%$ \\
\hline \multirow{5}{*}{$0-5$} & Figura pública: cantante & 0 & 2 & 0,0 & Alimentos y estimulantes & & 4 & 0,0 \\
\hline & $1^{\circ}$ ascendente: mamá, papá & 3 & 767 & 0,4 & Esp. público: escuela, cuadra & & 24 & 0,0 \\
\hline & $2^{\circ}$ ascendente: abuelos & 2 & 126 & 1,6 & Enseres y vestuario & & 36 & 0,0 \\
\hline & Genérico asc.: familiar & 2 & 48 & 4,2 & Cualidad o condición & & 23 & 0,0 \\
\hline & Cónyuge 1: esposo-a, señora & 5 & 105 & 4,8 & Esp familiar genérico: casa & & 191 & 2,1 \\
\hline $6-10$ & $1^{\circ}$ ascendente: padres, viejos & 9 & 103 & 8,7 & Salario/beneficio económico & 2 & 21 & 9,5 \\
\hline \multirow{2}{*}{$\begin{array}{l}11- \\
15\end{array}$} & 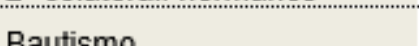 & & & & Ambito profesional & 16 & 122 & 13,1 \\
\hline & Bautismo & 3 & 20 & & Lapso vital & 16 & 106 & 15,1 \\
\hline \multirow{3}{*}{$\begin{array}{c}16- \\
20\end{array}$} & $3^{\circ}$ col descendente: sobrinos & 3 & 16 & 18,8 & Eventos y/o sucesos & 6 & 36 & 16,7 \\
\hline & $4^{\circ} \mathrm{col}$. ascendente: primos & 6 & 30 & 20,0 & Esp. procedencia: pueblo & 2 & 12 & 16,7 \\
\hline & $3^{\circ}$ col ascendente: tíos & 7 & 35 & 20,0 & & & & \\
\hline \multirow{2}{*}{$\begin{array}{l}21- \\
25\end{array}$} & & & & & Corporal & 5 & 23 & 21,7 \\
\hline & Amistad & 12 & 48 & 25,0 & $\begin{array}{l}\text { Mental de cognición } \\
\text { Mental de sensación }\end{array}$ & $\begin{array}{l}9 \\
5\end{array}$ & $\begin{array}{l}41 \\
21\end{array}$ & $\begin{array}{l}22,0 \\
23,8\end{array}$ \\
\hline $\begin{array}{l}26- \\
30\end{array}$ & $\begin{array}{l}2^{\circ} \text { descendente: nietos } \\
1^{\circ} \text { descendente: hijos }\end{array}$ & $\begin{array}{r}3 \\
66\end{array}$ & $\begin{array}{r}11 \\
226\end{array}$ & $\begin{array}{l}27,3 \\
29,2\end{array}$ & Mental de volición & 4 & 15 & 26,7 \\
\hline \multirow{3}{*}{$\begin{array}{l}31- \\
35\end{array}$} & Afinidad: suegros, cuñados & 9 & 29 & 31,0 & Aficiones & 5 & 15 & 33,3 \\
\hline & Cónyuge 2 : marido, mujer & 6 & 19 & 31,6 & Animales & 2 & & 33,3 \\
\hline & & & & & Esp intimidad: cuarto & 4 & 12 & 33.3 \\
\hline \multirow{6}{*}{+36} & Noviazgo & 9 & 24 & 37,5 & & & & \\
\hline & Laboral & 6 & 17 & 35,3 & Gen. de interés: cosa & 8 & 22 & 36,4 \\
\hline & Vecindad & 2 & 5 & 40,0 & Vehículo & 5 & 11 & 45,5 \\
\hline & Transmisión de saberes & 15 & 29 & 51,7 & & & & \\
\hline & Gen. grupo: contemporáneos & 2 & 2 & 100,0 & & & & \\
\hline & $\mathrm{N}: 288 / 2666(11 \%) \quad \Sigma$ & 195 & 1925 & 10 & $\Sigma$ & 93 & 741 & 12,5 \\
\hline
\end{tabular}

Fuente: Elaboración propia.

Por una parte, el uso del posesivo con entidades más humanas [+HUM] permiten indicar favoritismo por una figura pública (cantantes); relaciones consanguíneas genéricas (antepasados, familiares), ascendentes (mamá, abuelo), colaterales de 2으, 3ำ y 4 으 grado (hermanos, prima, tía, sobrino) y descendentes (hijos, nieta); parentesco por afinidad directa (esposo, mujer) e indirecta (suegra, cuñado); así como diversas relaciones sociales (bautismo, amistad, noviazgo, laboral, vecindad y transmisión de saberes). 
En la tabla 4, los vínculos se han ordenado de forma ascendente según el porcentaje. De acuerdo con los datos, la posposición es más frecuente cuando establece relaciones de proximidad social (+36\%), afinidad conyugal (cónyuge 32\%, parientes políticos 31\%), consanguinidad descendente (nietos $27 \%$, hijos $29 \%$ ) y amistad (25\%); ejemplifico estas relaciones en (3a-h):

(3) a. creo que la generación mía sí se ... ha sufrido unos cambios (CA-C3MB)

b. yo... comparo lo... los horarios de los alumnos míos ahorita (MB-B3FB)

c. la amiga mía, esta que era vecina mía y yo, fuimos (CA-B1FA)

d. tú tienes por ejemplo el chofer mío, él vive en una casita (MB-D1FA)

e. el suegro mío se parecía mucho a ... a Gómez físicamente (MD-C3MB)

f. en casa no se alza la voz más que la mujer mía y yo (MB-C5MB)

g. Tiene tres hijos, la nieta mía. Tres chiquitos (CA-D5FA)

h. igual que su padre. Los dos hijos míos salieron igual que él (MB-B3FA)

Como se observa, el aumento del uso pospuesto está inversamente asociado con los vínculos consanguíneos ascendentes, de modo que su empleo podría interpretarse como un recurso expresivo para marcar un grado mayor de familiaridad en aquellas relaciones sociales no parentales. En el diagrama 1 se grafica esta correspondencia:

Diagrama 1. Posesivo posnominal y familiaridad expresiva en entidades [+HUM]

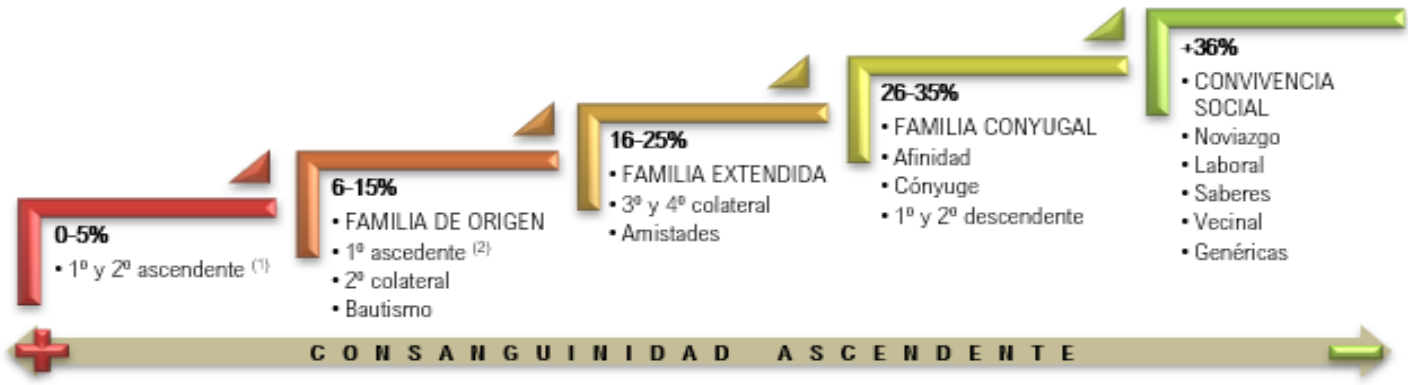

Fuente: Elaboración propia

Por otra parte, el posesivo con entidades no humanas [-HUM] suele hacer referencia a pertenencias o propiedades físicas e intelectuales del hablante. En este caso, agrupé los sustantivos 
en animales (perro), alimentos y estimulantes (arepa, cigarrillo), enseres y vestuario (cama, chaqueta), vehículos (carro); espacios: público (escuela), familiar (casa), procedencia (pueblo), intimidad (cuarto); beneficio económico (beca, sueldo), ámbito profesional (carrera, trabajo), eventos y sucesos (cumpleaños, detención); lapso vital (época, infancia, vida), corporal (mano, pulso); cualidad o condición (carácter, maldad); procesos mentales: sensación (desencanto), cognición y lenguaje (recuerdos, opinión), volición (anhelo); aficiones (hobby) y genéricos de interés (cosa, problema).

En la tabla 4, se observa que el uso pospuesto es favorecido por entidades [-HUM] utilizadas para hacer referencia a posesiones inherentes al ámbito privado -vehículo (45,5\%), intereses (36\%), espacio de intimidad, mascotas y aficiones (33\%)-, y a procesos psicofísicos del hablante (21-30\%); en (4) ofrezco algunos ejemplos:

(4) a. entonces cogí el carro mío para dar unas vueltas por ahí (MB-B3MA)

b. me peleo con él porque se lleva... las cosas mías, se las lleva (MB-C1MA)

c. este es el cuarto mío, ella dormía aquí y aquí duermo yo, ahora (MD-B5MB)

d. los perros se guindan a pelear, tumban el perro mío pa' un lado (CA-B5MB)

e. Yo cogí planta baja porque la... la... la vida mía son las matas (MB-B3FA)

f. es más voluntad mía que de los bailarines (MD-A3MB)

g. Matemáticas, que era el... la... el fastidio mío, a mí no me gustaban (MD-B1FA)

h. ese... es el pensamiento mío, y siempre se lo he dicho (MD-B5MB)

i. y les gustó la voz mía y empezaron [?]: “¡Oye, qué bien cantas!” (CA-A3MA)

Con entidades [-HUM], el uso del pospuesto también muestra un continuum que va de la vida pública a la privada (cf. diagrama 2) y su empleo resulta en un refuerzo de la proximidad en aquellas entidades concretas de usufructo exclusivo del hablante o abstractas referentes a su íntima introspección (bien común vs. utilidad individual): ${ }^{11}$

\footnotetext{
${ }^{11}$ La categorización está sustentada en la jerarquía de la motivación humana (cf. Maslow, 1943).
} 
Diagrama 2. Posesivo posnominal y expresión de proximidad en entidades [-HUM]

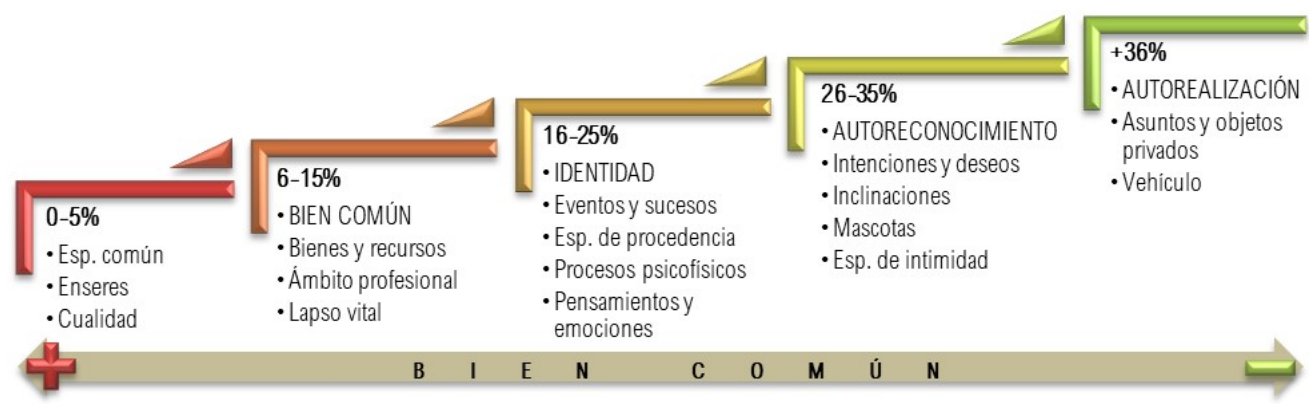

Fuente: Elaboración propia

En la tabla 4 también se advierte que algunas variantes registran frecuencias de posposición nulas o demasiado bajas frente a la anteposición. Al respecto, he seguido las acciones sugeridas por Guy (1988): identificar y excluir los contextos invariables y minimizar el número de factores explicativos. Por esta razón, en un segundo ajuste de los datos, he excluido los casos que muestran un porcentaje de uso inferior a 5\% y reagrupé las categorías restantes según la familiaridad expresada en las relaciones dentro del mismo rango de porcentajes. ${ }^{12}$ La redistribución se ofrece en la tabla 5:

Tabla 5. Posesivo posnominal: Redistribución de la variable relación semántica

\begin{tabular}{|c|c|c|}
\hline $\begin{array}{l}\text { RELACIÓN SEMÁNTICA (3 g.d.I.: } 7,815) \\
\text { N: } 272 / 1340(20 \%)\end{array}$ & Posin & $r \%$ \\
\hline${ }^{[+\mathrm{Hum}]}$ Familia de origen (padres, hermanos, bautismo) & \multirow{2}{*}{$71 / 635$} & \multirow{2}{*}{-7.911} \\
\hline [-Hum] Bien común (progreso y desarrollo personal) & & \\
\hline [+Hum] Familia extendida (parentela, amistades) & \multirow{2}{*}{$55 / 262$} & \multirow{2}{*}{0.321} \\
\hline 16 a $25 \%$ [-HuM] Identidad (autobiografía y emocionalidad) & & \\
\hline [+Hum] Familia conyugal (cónyuge, afines y descendientes) & \multirow{2}{*}{$99 / 333$} & \multirow{2}{*}{4.930} \\
\hline 26 a $35 \%$ [-Hum] Autorreconocimiento (propósitos e independencia) & & \\
\hline [+Hum] Convivencia social (noviazgo, laboral, saberes, vecindad) & \multirow{2}{*}{$47 / 110$} & \multirow{2}{*}{6.143} \\
\hline [-Huм] Autorrealización (determinación y utilidad individual) & & \\
\hline $\mathrm{X}^{2}=87,218 \quad$ LRT $=85,516 \quad \Phi, \mathrm{V}=0,252 \quad \mathrm{C}=0,245$ & $p=0.0$ & $000<.05$ \\
\hline
\end{tabular}

Fuente: Elaboración propia

El análisis indica una asociación significativa entre la posición del posesivo y la variable semántica ( $p$ $<$.05). Los resultados coinciden con los ya descritos: la tendencia a la posposición parece aumentar

\footnotetext{
${ }^{12}$ Esto con el propósito de asegurar la fuerza demostrativa de las correlaciones (Cf. Demonte, 2000; Guirado, 2009).
} 
con los sustantivos que expresan convivencia social y autorrealización $(r=6.1)$ y con entidades que hacen referencia a las relaciones derivadas del núcleo conyugal y al autorreconocimiento del hablante $(r=4.9)$.

\subsubsection{El posesivo posnominal y la función sintáctica}

Para el análisis de la función sintáctica del grupo nominal, clasifiqué los casos en: i. sujeto; ii. complemento directo e indirecto; iii. otros complementos verbales y de núcleo; iv. atributo; v. incisos y topicalizaciones. En la tabla 6 se muestran los resultados:

Tabla 6. Distribución del posesivo posnominal de 1aㅗ sg. según la función sintáctica

\begin{tabular}{|c|c|c|c|}
\hline $\begin{array}{l}\text { FUNCIÓN SINTÁCTICA (4 g.d.I.: 9.488) } \\
\text { N: } 272 / 1340(20 \%)\end{array}$ & Pos/n & $r$ & $\%$ \\
\hline Sujeto & $114 / 487$ & 2.1 & 23 \\
\hline Complemento directo e indirecto & $46 / 278$ & -1.7 & 16,5 \\
\hline Otros complementos & $47 / 428$ & -5.8 & 11 \\
\hline Atributo & $50 / 95$ & 8.1 & 53 \\
\hline Inciso & $15 / 52$ & 1.6 & 29 \\
\hline$X^{2}=92,033 \quad$ LRT $=82,443 \quad \Phi, V=0,262 \quad C=0,254$ & \multicolumn{3}{|c|}{$p=0.000<.05$} \\
\hline
\end{tabular}

Fuente: Elaboración propia

El atributo registra la tendencia más alta de posposición (53\%) y los datos indican una notable asociación de dependencia del posesivo pospuesto cuando modifica grupos nominales en esta función ( $r=8.1)$. Asimismo, se observa que la función de sujeto $(r=2.1)$ y los incisos y topicalizaciones $(r=1.6)$ también contribuyen al empleo:

(5) a. Y bueno ellos pueden ser amigos míos ATR (CA-B5FA)

b. El primer marido mío sus vivió toda la vida allí (MB-B3FB)

c. más pequeña que este muchacho que vino pa acá, el nieto mío INC (MD-D5FB)

\subsubsection{El posesivo posnominal y las variables extralingüísticas}

En la tabla 7 se muestran los datos del pospuesto según cada una de las variables extralingüísticas: 
Tabla 7. Distribución del posesivo posnominal según las variables extralingüísticas

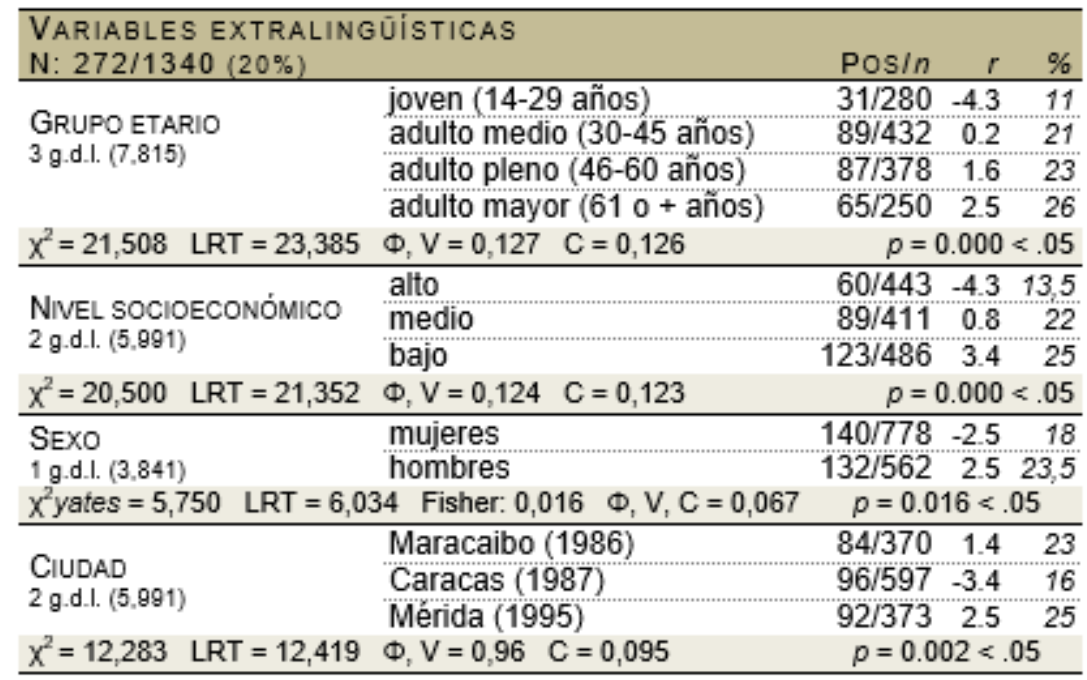

Fuente: Elaboración propia

Según los resultados, los adultos mayores, los hombres y los oriundos de Mérida $(r=2.5)$ muestran cierta inclinación hacia la forma pospuesta; esta tendencia aumenta en el nivel bajo ( $r=3.4)$. En el diagrama 3, se cotejan los porcentajes de cada variante por variable:

Diagrama 3. Porcentaje del posesivo ante/posnominal en las variables extralingüísticas

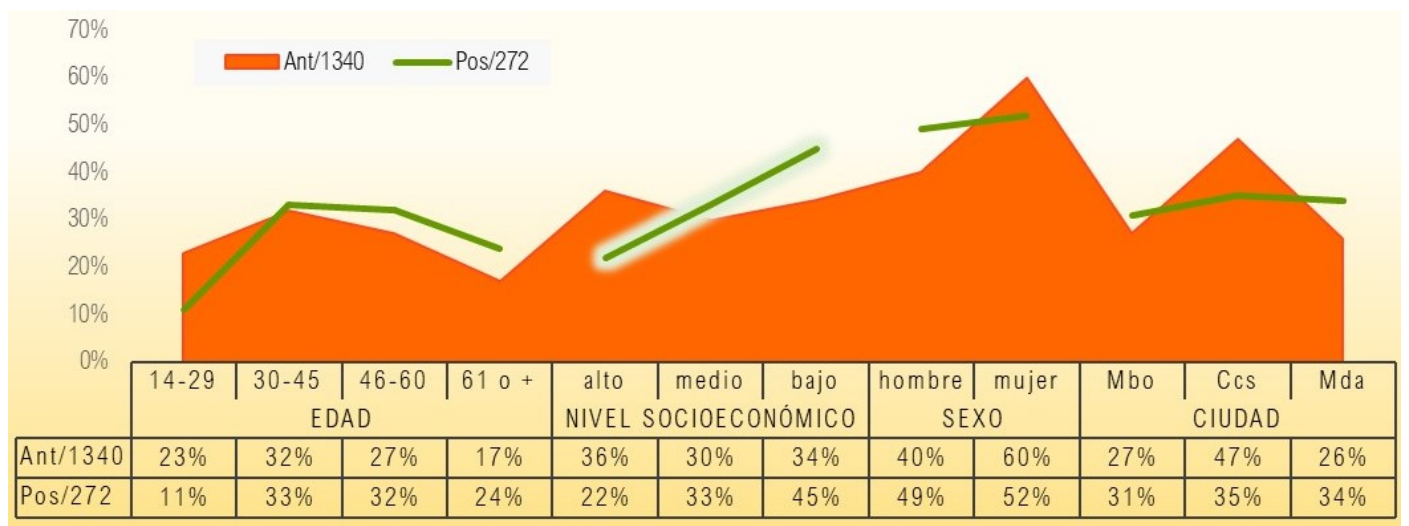

Fuente: Elaboración propia

En el diagrama 3, la línea de posposición se eleva fuera del área de anteposición en las variantes cuyo residuo es positivo. El nivel socioeconómico es, justamente, el único factor que ostenta un 
patrón inverso de distribución de las proporciones. Asimismo, aunque la ciudad dibuja una curva similar en ambos usos, la posposición se eleva en merideños y maracuchos, en contraste con los hablantes capitalinos.

\subsubsection{El posesivo posnominal: análisis inferencial}

Utilicé un análisis de regresión logística binomial (up\&down) para establecer la contribución conjunta de las variables a la posposición. Procesé los datos con Rbrul (Johnson, 2009), un programa estadístico que puede aplicar tanto el modelo tradicional de efectos fijos como uno lineal generalizado de efectos mixtos.

El modelo de efectos fijos presupone que los datos de los predictores son, efectivamente, independientes, principio que impide determinar si la frecuencia de un factor es azarosa o producto de una variación individual. El modelo de efectos mixtos, en cambio, incluye efectos aleatorios que permiten considerar esta variación sin distorsionar los coeficientes de los factores fijos. A continuación, se prueba un primer modelo de efectos mixtos con el hablante como efecto aleatorio, que incluye las seis variables propuestas:

Tabla 8. Contribución conjunta de las variables al POS_POS_1ass. - Modelo 1

\begin{tabular}{|c|c|c|}
\hline CoRrida & $p$-valor $<.05$ & prop. general: $0.203 ; \mathrm{N}: 272 / 1340$ \\
\hline up & Hab $\mid R S\left(1.5 \times 10^{-16}\right)+F S\left(2.69 \times 10^{-14}\right)+N S\left(1.55 \times 10^{-04}\right)+5$ & $\mathbf{S x}(0,00878)+\mathbf{C i}(0.0205)+\mathrm{GE}(0.0215)$ \\
\hline Down & Hab |RS $\left(3.9 \times 10^{-15}\right)+F S\left(1.83 \times 10^{-14}\right)+N S\left(1.66 \times 10^{-06}\right)+5$ & $\mathrm{Sx}(0,00230)+\mathrm{GE}(0.0131)+\mathrm{Ci}(0.0205)$ \\
\hline \multicolumn{3}{|c|}{ Intercepción [aleatorio.]: $0.775=$ gdl $17=$ Input: 0.249 = Desviación: 1080.5} \\
\hline
\end{tabular}

Fuente: Elaboración propia

En la tabla 8, se aprecia la disposición de las variables según los distintos índices de probabilidad. Aunque todas las variables son consideradas significativas, en el ajuste del modelo se advierte que la convergencia de los datos falla $(0.005>0.002)$. Barr, Levy, Scheepers y Tily $(2013$, p.261) explican que el modelo puede tornarse inidentificable cuando no hay datos suficientes para estimar los 
efectos. ${ }^{13} \mathrm{Al}$ comparar los $p$-valores, se observa que la posición de la variable grupo etario difiere en ambas corridas. De esta forma, la reducción de las posibilidades combinatorias puede tener origen en la menor proporción de casos en los hablantes jóvenes (cf. §4.1.1., supra). He usado Language, Variation Suite (Scrivner \& Díaz-Campos, 2016) para obtener un árbol de inferencia condicional (AIC) de los predictores extralingüísticos que me ayude a verificar esta hipótesis:

Diagrama 4. Árbol de inferencia condicional con las variables extralingüísticas

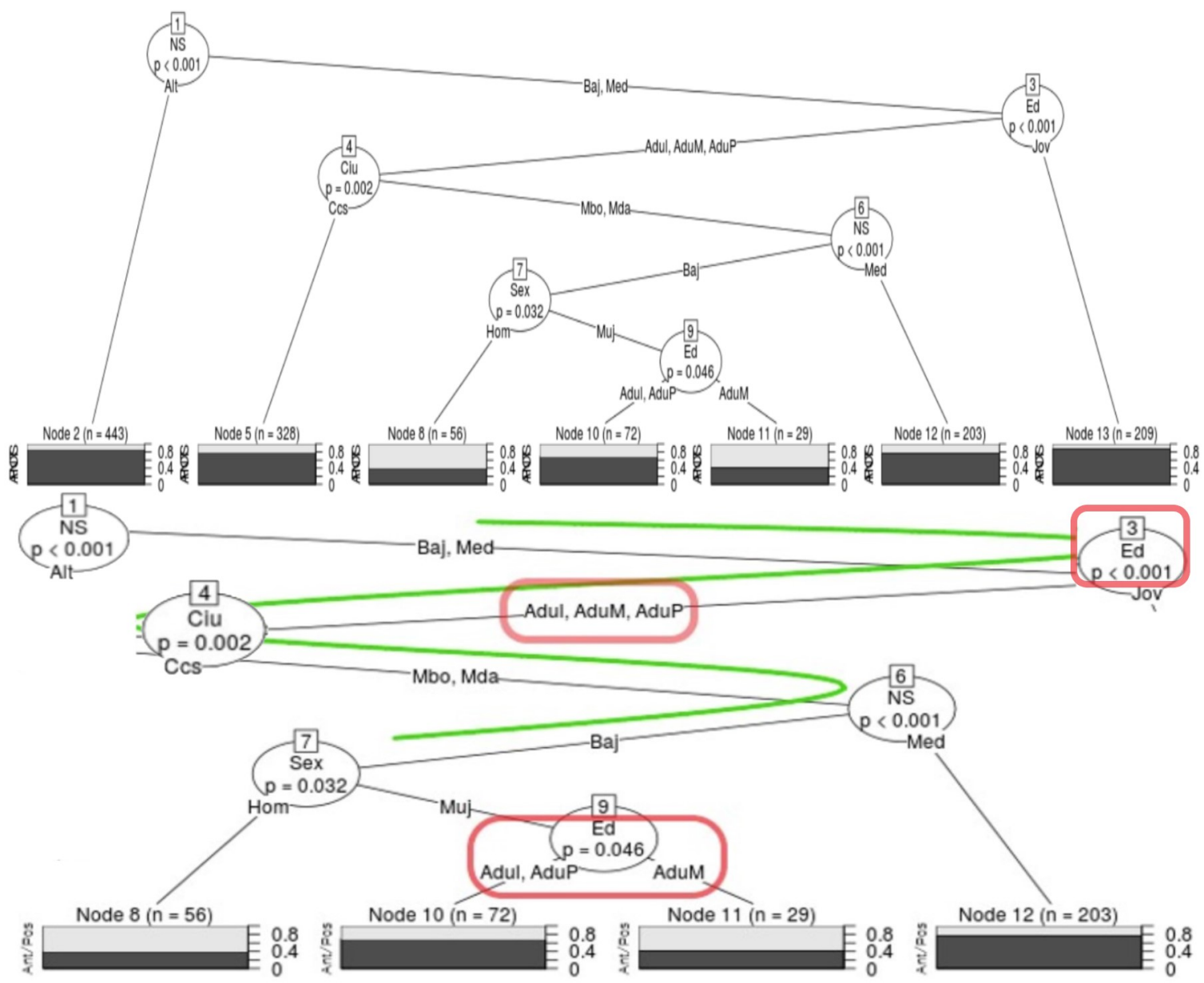

Fuente: Elaboración propia

\footnotetext{
${ }^{13}$ Aunque los datos se han ajustado suficientemente, las ocurrencias no superan los 97 enunciados. Para Paolillo (2013, p. 97), el margen mínimo para realizar un análisis de efectos aleatorios es "100 tokens per speaker".
} 
En el $\mathrm{AIC}^{14}$ se observa que el factor más relevante resulta ser, efectivamente, el nivel socioeconómico (Nodo 1). El esquema arbóreo se desarrolla en dos direcciones: a la izquierda del diagrama 4, se concentran los casos del nivel alto y, a la derecha, se extienden las particiones asociadas los niveles medio y bajo. A su vez, los hablantes son divididos en dos grandes grupos etarios (Nodo 3): jóvenes, por una parte, y todos los adultos por otra. Las siguientes particiones dividen a los adultos según la ciudad (Nodo 4); de nuevo nivel socioeconómico (Nodo 6); sexo (Nodo 7); y, otra vez, edad (Nodo 9).

La incongruencia de los datos en el análisis de regresión se explicaría, entonces, en estas particiones. Aunque los hablantes adultos inclinan la media bruta de su grupo, la interacción restringe su correlación con mujeres de nivel bajo oriundas de Mérida o Maracaibo. Véanse las estimaciones del grupo etario: en el nodo 3 , el p-valor está por debajo del umbral $(p<0.001)$, mientras que, en el nodo 9, el efecto predictor se acerca claramente al límite establecido (0.046). El efecto aleatorio seguramente incorpora estas diferencias individuales y ajusta su efecto en menos de la mitad y, como tal, el grupo etario deja de tener significancia y aumenta, así, la estimación de las otras variables.

En virtud de que la elección del diseño de los datos con efectos aleatorios no está sujeta a criterios preestablecidos (Barr et al., 2013), hice un segundo análisis sin incluir el grupo etario, con lo cual creo haber fortalecido el diseño metodológico, pues los cálculos del programa no arrojaron errores de convergencia con este segundo modelo. ${ }^{15}$

En la tabla 9, se muestran las variables que registran mayor probabilidad de contribuir, simultáneamente, al uso del posesivo pospuesto de 1a sg. Las mismas están ordenadas de mayor a menor significancia, según el p-valor. Similar al primer modelo, las cinco variables resultaron significativas, ya que los valores están por debajo del límite establecido $(p<0.05)$. La posposición

\footnotetext{
${ }^{14}$ Este procedimiento permite visualizar la interacción compleja de las variables porque estima la distribución del uso a través de una partición recursiva (cf. Strobl, Malley \& Tutz, 2009; Tagliamonte \& Baayen, 2012).

15 Paolillo $(2013$, p.97) respalda la decisión metodológica de excluir factores o crear subgrupos de la muestra, siempre que estos supuestos metodológicos contribuyan a la interpretación de los datos: "We will come to see that the data do not strongly determine the results of the statistical analysis and that certain assumptions, the selection of which should be guided by the research design, are every bit as important".
} 
del posesivo se correlaciona fuertemente con las variables lingüísticas, mientras que el más influyente de los factores externos es el nivel socioeconómico.

Tabla 9. Contribución conjunta de las variables al POS_POS_1asg. - Modelo 2

\begin{tabular}{|c|c|c|c|c|}
\hline Variables & Variantes & $\begin{array}{l}\text { Coef.B } \\
(\log \text {-odds) }\end{array}$ & $\begin{array}{c}\text { Peso prob. } \\
(>.5)\end{array}$ & $\begin{array}{c}\text { p-valor } \\
(<.05) \\
\end{array}$ \\
\hline \multirow{2}{*}{ RELACIÓN SEMÁNTICA } & $\begin{array}{l}\text { [+Hum] Convivencia social } \\
\text { [-Hum] Autorrealización }\end{array}$ & 0.932 & $0.717 \leftarrow$ & \multirow{2}{*}{$2.34 \times 10^{-15}$} \\
\hline & $\begin{array}{l}\text { [-Hum] Familia conyugal } \\
\text { [-Hum] Autorreconocimiento }\end{array}$ & 0.367 & 0.591 & \\
\hline \multirow{3}{*}{ FUNCIÓN SINTÁCTICA } & Atributo & 1.354 & $0.795 \leftarrow$ & \multirow{3}{*}{$8.33 \times 10^{-15}$} \\
\hline & Inciso & 0.358 & 0.589 & \\
\hline & Sujeto & 0.036 & 0.509 & \\
\hline NIVEL SOCIOECONÓMICO & Bajo & 0.828 & $0.696 \leftarrow$ & $6.48 \times 10-06$ \\
\hline SEXO & Hombres & 0.341 & 0.584 & 0.007 .25 \\
\hline \multirow{2}{*}{ CIUDAD } & Maracaibo & 0.330 & 0.582 & \multirow{2}{*}{0.0352} \\
\hline & Mérida & 0.116 & 0.529 & \\
\hline Hablante $(n: 98)$ & {$\left[\begin{array}{llllll} & A & L & E & A & T\end{array}\right.$} & O R I 0 & ] & Interc:: 0.864 \\
\hline
\end{tabular}

Fuente: Elaboración propia

El segundo grupo de datos corresponde a los pesos probabilísticos y la probabilidad logarítmica o log-odds (Coef. B). En la tabla 9, únicamente se incluyen los factores que favorecen el uso posnominal con pesos superiores a .5 y coeficientes positivos. ${ }^{16}$ De acuerdo con ambos índices, las relaciones semánticas que expresan convivencia social y autorrealización, la función sintáctica de atributo y el nivel bajo son las variantes que registran la correlación de uso más sólida con la posposición.

Finalmente, las categorías y números que se especifican debajo de la tabla 9 están relacionadas con el ajuste del modelo propuesto. La probabilidad (input) de que los hablantes de los tres dialectos usaran el posesivo posnominal en la década entre 1986 y 1996 no es muy alta ( $\pm 30 \%)$; sin embargo, es mayor a la registrada con la inclusión del grupo etario (cf. tabla 8). Al agregar el

\footnotetext{
${ }^{16}$ Los pesos indican la significancia estadística de las variantes, mientras que los coeficientes B expresan el grado de asociación y la potencia. A diferencia del peso probabilístico, este índice ofrece una medida de tendencia balanceada, cuando el coeficiente $B$ es positivo, es mayor la intensidad de la relación entre la categoría y la posposición.
} 
efecto aleatorio, la intercepción y la varianza explicada $\left(R^{2}\right)$ también aumentan con el segundo modelo. La desviación, el logaritmo de verosimilitud (log.Lik) y el Criterio de información de Akaike (AICC) indican que el modelo proporciona un buen ajuste y predicciones confiables.

En conclusión, la inclusión del hablante como efecto aleatorio -así como la exclusión de la variable grupo etario- mejora los índices de correlación y evita que la edad aparezca con una significancia sobrestimada. No obstante, dado que la proporción de la posposición (gran prop.) solo alcanza el 20,3\%, los intervalos de confianza son mucho más amplios y no se deben sacar, tampoco, conclusiones definitivas del análisis

\subsection{Segunda parte: otros usos expresivos del posesivo de $1 \underline{a} \mathrm{sg}$.}

\subsubsection{Alternancia del posesivo posadverbial}

En la muestra, documenté doce (12) usos de adverbios ante de mí: antes (2), cerquita (1), debajo (1), dentro (1), después (3), detrás (2), encima (2). Con posesivo pospuesto solo registré casos con dos adverbios: atrás (1) y encima (2). En (6a) muestro el caso aislado con atrás y en (6b, c) la alternancia con los casos de encima:

(6) a. salí corriendo por todo el patio y mami atrás mío corriendo (MB-A1FB)

b. yo sentía... que él iba se acostaba encima de mí ¿no? (MB-C3FA)

c. y me pasó el buey, me pasó por encima mío (MD-D5FB)

Adicionalmente, encontré tres enunciados con locuciones que pueden usarse con el posesivo antepuesto, con el tónico pospuesto o con el grupo de mí. En el corpus, a espaldas 'detrás' y al lado 'cerca' alternan solo con el antepuesto y el pospuesto (7a-d); mientras que al alcance y a la vistaambos 'cerca' (7e)- únicamente lo hacen con el antepuesto; finalmente, a excepción se registra solo con el pospuesto (7f):

(7) a. si crees que la puedes tratar a mis espaldas, trátala (CA-A5MA)

b. si lo hace lo hará a espaldas mía, no sé, y no me consta (CA-A5MA)

c. siempre está a mi lado cuando yo lo necesito (MD-A1FB)

d. Pero pa'l lado mío, no han habido problemas (CA-D5FA) 
e. tengo algo a mi ... así, a mi ... a mi vista, a mi alcance, yo lo agarro (CA-A5FA)

f. fue bastante fuerte para nosotros, yo diría que a excepción mía (CA-B3MA)

\subsubsection{Alternancia del posesivo posverbal}

En el corpus, no abundan los casos en los que el posesivo apreciativo alterna con grupos preposicionales encabezados por las preposiciones de/por mí. Registré diecinueve (19) cláusulas con un núcleo verbal que rige el grupo preposicional de mí: acordarse (5), enamorarse (2), burlarse (1), quejarse (1), apoderarse (1), depender (2), hablar (1), tomar posesión (1), recordar/querer/saber $+\mathrm{GN}(3)$, estar pendiente/enamorado (2); mientras que solo encontré un caso con saber + GN + posesivo pospuesto. En $(8 \mathrm{a}, \mathrm{b})$ ofrezco los ejemplos de la única alternancia:

(8) a. otras personas saben algo de mí (CA-B5MB)

b. yo no sé nada de él y él [no sabe] nada mío (MB-B5FB)

Por último, los hablantes no suelen usar la función de complemento agente para referirse a sí mismos. En el corpus, solo hay tres casos, uno con el grupo preposicional por mí (9a) y dos con el posesivo tónico $(9 b, c)$; los dos primeros pertenecen al mismo hablante:

(9) a. todo, todo esto lo hice yo mismo, todo preparado, el material, por mí (CA-D5MB)

b. Eso ... eso es frisado mío también, y el piso todo, todo, todo (CA-D5MB)

c. ella ha sido... muy consentida, no tanto mía ¿no? (MD-D3FA)

\subsubsection{Posesivo enfático (redundante y ponderativo)}

Registré un solo (1) caso de posesivo redundante en el corpus, emitido por una adulta mayor de clase media oriunda de Maracaibo:

(10) por lo regular era con mi hermano mío mayor (MB-D3FB)

En cambio, identifiqué un mayor número de usos del ponderativo. En la tabla 10 se observa que los hablantes caraqueños registran el mayor número de estos posesivos enfáticos (46\%) y la mayoría puede sustituirse por artículos (63\%); en cambio, los merideños aportan un $31 \%$ de casos, la 
mayoría de los cuales puede omitirse (59\%); mientras, los maracuchos documentan menos usos (23\%), distribuidos equitativamente entre omisibles y sustituibles (50\%): ${ }^{17}$

Tabla 10. Usos del posesivo ponderativo

\begin{tabular}{cccc}
\hline Ciudad & mi $~$ & mi art & Total \\
\hline MARACAIBO & $11(50 \%)$ & $11(50 \%)$ & $22(23 \%)$ \\
CARACAS & $16(37 \%)$ & $27(63 \%)$ & $43(46 \%)$ \\
MÉRIDA & $17(59 \%)$ & $12(41 \%)$ & $29(31 \%)$ \\
\hline$p=0.191>.05 \sum 44(47 \%)$ & $50(53 \%)$ & 94 \\
\hline
\end{tabular}

Fuente: Elaboración propia

Buena parte de estos empleos enfáticos permite ratificar un hábito, costumbre o rutina (nadar, tomar café, fumar). Como se aprecia en (11), el énfasis suele estar reforzado con el uso del diminutivo:

(11) a. me doy mi ... zambulladita <sic> de vez en cuando (MB-B3FA)

b. friego mis coroticos del café, hago mi cafecito, cuando lo tengo (CA-D5FB)

c. cuando vengo con Ana Julia yo prendo mi cigarrito y ella jamás (MD-B3FA)

De esta forma, lo frecuente es que coincida más de un recurso para intensificar la característica. En (12), por ejemplo, los hablantes acuden a algunas frases fijas e introducen el posesivo ponderativo para intensificar el carácter inherente de lo expresado:

(12) a. me daba mi bomba, porque de cuatro y media a cinco, ya era media hora nada más (CA-A5MB)

b. Yo pienso seguir tocando, matando mis tigritos y demás (MD-A1MA)

Asimismo, la cualidad ponderada suele estar expresada a través de procesos materiales:

(13) a. Era fascinante montarse en mi tranvía y... y venir ¿no? (MB-D1MA)

b. brincaba mi mecate, jugábamos gárgaro, escondido (CA-C3FA)

\footnotetext{
17 Lo he denominado ponderativo porque comparto la interpretación de Fernández Ramírez ([1951]1987, p.91): "utilización de las mismas formas átonas con fines expresivos, uso que en el estilo coloquial y popular alcanza extraordinario desarrollo, con los más variados matices de ternura, de ironía, de encarecimiento, etc. El valor de los posesivos se acerca en algunos de estos casos al de los indefinidos cuantitativos y ponderativos".
} 
c. monté mi taller y hacía las colecciones y las vendía afuera (MD-B1FB)

Con frecuencia, la práctica rutinaria está asociada al emprendimiento y la constancia laboral, de modo que el énfasis recae en la valoración misma del trabajo:

(14) a. me empujaba con mis paquetes de periódico en la cabeza (CA-B5MB)

b. trabajando haciendo mis arepas y las cosas y ... buscando la vida (CA-D5MA)

c. me fabriqué un cajón y compré mi cepillo, mis cremas y me iba a limpiar zapato (MD$\mathrm{B} 5 \mathrm{MB})$

El énfasis valorativo también está asociado a la consecución de una etapa o logro educativo o al cumplimiento de un deber:

(15) a. yo cursé mis tres intensivos de inglés, los hice (MB-A1FA)

b. Estudié desde primero hasta mi sexto grado y me fue de maravilla (CA-A5FB)

c. hice mi aprendiz de farmacia, luego el auxiliar y... así (MD-C3MB)

Otros empleos aparecen para reforzar un atributo:

(16) a. Y me ponían mis alitas y mis sandalitas y mi trajecito largo (MB-C1FB)

b. en ese tiempo yo tenía mi vista buena. Yo veía (CA-D5MB)

c. yo tenía mis adornos de cristal ¿no? (MD-B3FA)

En otros casos, en cambio, puede usarse para encarecer una característica inesperada:

(17) a. yo iba también en mi bestia, montada como si fuera varón (MB-D3FB)

b. yo llegué muy campante con mis rabipelados a mi casa (CA-A3MA)

c. me facilitan... mi mi pasaje, e... mi estadía en hotel allá, mis viáticos (MD-A5MB)

A continuación, presento un ejemplo en su contexto amplio, el cual permite advertir, sin mayor explicación, el matiz afectivo del posesivo para ponderar la bandera como objeto protagonista del relato y móvil de la emoción transmitida: 
(18) si uno ve la bandera de Venezuela afuera de su país, eso es para uno... bueno grande pues, y yo me acuerdo que... yo no entendía el en mi primera competencia afuera por qué los muchachos, o sea el entrenador le ponía a uno la bandera al frente, o sea uno estaba compitiendo y le ponían el en la en la grada la bandera... después uno... pues yo me acuerdo de que en... los centroamericanos del año pasado no lo hicieron... entonces yo me llevé mi bandera y la puse ahí... le le pedí a los muchachos que la pusieran ahí porque no llevábamos bandera y entonces me la pusieron ahí, entonces a uno le da como más espíritu pues (MD$\mathrm{A} 5 \mathrm{MB})$

Asimismo, en el ejemplo (19), el uso del posesivo permite realzar el objeto central de la anécdota, en esta oportunidad, para intensificar su alcance humorístico:

(19) Hay un cuento muy cómico ... que le pasó a mi mamá, conmigo. Yo agarré una vez ... empezaron en esa época a salir los desodorantes de bolita. Entonces vengo yo <risas>, sin decirle nada a mi mamá, y le saco la bolita al desodorante y le vuelvo a poner la tapa. Y se la pongo en su baño, ¿no? <risas>. Y me voy a jugar metras <risas> con mi bolita de desodorante, que era una cristalina, pues <risas>. Tacatá, tacatá, tá. Esa noche me [...] me pelaron porque mi mamá se b.., iba a salir esa noche con mi papá, se bañó y cuando se fue a echar desodorante ifuissss! se le chorreó todo el desodorante, ¿no? (CA-B1MA)

Para concluir el análisis del uso ponderativo, presento las frecuencias absolutas de este empleo según las variables sociales:

Tabla 11. Usos del posesivo ponderativo según las variables sociales

\begin{tabular}{|c|c|c|c|c|c|c|c|c|c|c|c|c|c|c|c|}
\hline \multirow{3}{*}{$\begin{array}{r}\text { SEXO } \\
\text { GE } \\
\mathrm{NSICIU}\end{array}$} & \multicolumn{6}{|c|}{ Hombres } & \multicolumn{7}{|c|}{ Mujeres } & \multirow{3}{*}{$\Sigma$} & \multirow{2}{*}{ Total. } \\
\hline & \multicolumn{3}{|c|}{ 14-45 años } & \multicolumn{3}{|c|}{$460+$} & \multirow[t]{2}{*}{$\Sigma$} & \multicolumn{3}{|c|}{$14-45$} & \multicolumn{3}{|c|}{$460+$} & & \\
\hline & MB & $\mathrm{CA}$ & $M D$ & $\mathrm{MB}$ & CA & MD & & MB & CA & MD & MB & CA & MD & & $\%$ \\
\hline alto & & 2 & 4 & 1 & 1 & 1 & 9 & 3 & 1 & 4 & 4 & 1 & & 13 & 22 \\
\hline medio & & 4 & 1 & 1 & & 1 & 6 & 1 & 4 & 6 & 2 & 2 & 2 & 21 & 27 \\
\hline bajo & 2 & 4 & 9 & 5 & 3 & 1 & 25 & 3 & 7 & & & 10 & & 20 & $48 \quad 51$ \\
\hline$n$ & 2 & 10 & 14 & 7 & 4 & 3 & 40 & 7 & 16 & 10 & 6 & 13 & 2 & 54 & 94 \\
\hline$\%$ & & 28 & & & 15 & & $43 \%$ & & 35 & & & 22 & & $57 \%$ & \\
\hline
\end{tabular}

Fuente: Elaboración propia 
En la tabla 11 se observa que la mitad de los casos se registran en el nivel socioeconómico bajo (51\%); asimismo, los hablantes entre 14 y 45 años son quienes suman los porcentajes de uso más altos (63\%). Las mujeres emplean un poco más el posesivo ponderativo en la muestra, la mayoría de ellas son caraqueñas de clase baja; no obstante, las merideñas de las clases media y alta, aunque menos, también contribuyen al empleo. Los hombres, en cambio, concentran la mayor cantidad de casos en el nivel bajo; siendo los andinos de esta clase social quienes aportan un número sustancial de ponderativos. La correlación entre la edad y nivel socioeconómico se aprecia en el diagrama 5:

Diagrama 5. Correlación de factores sociales con el posesivo ponderativo

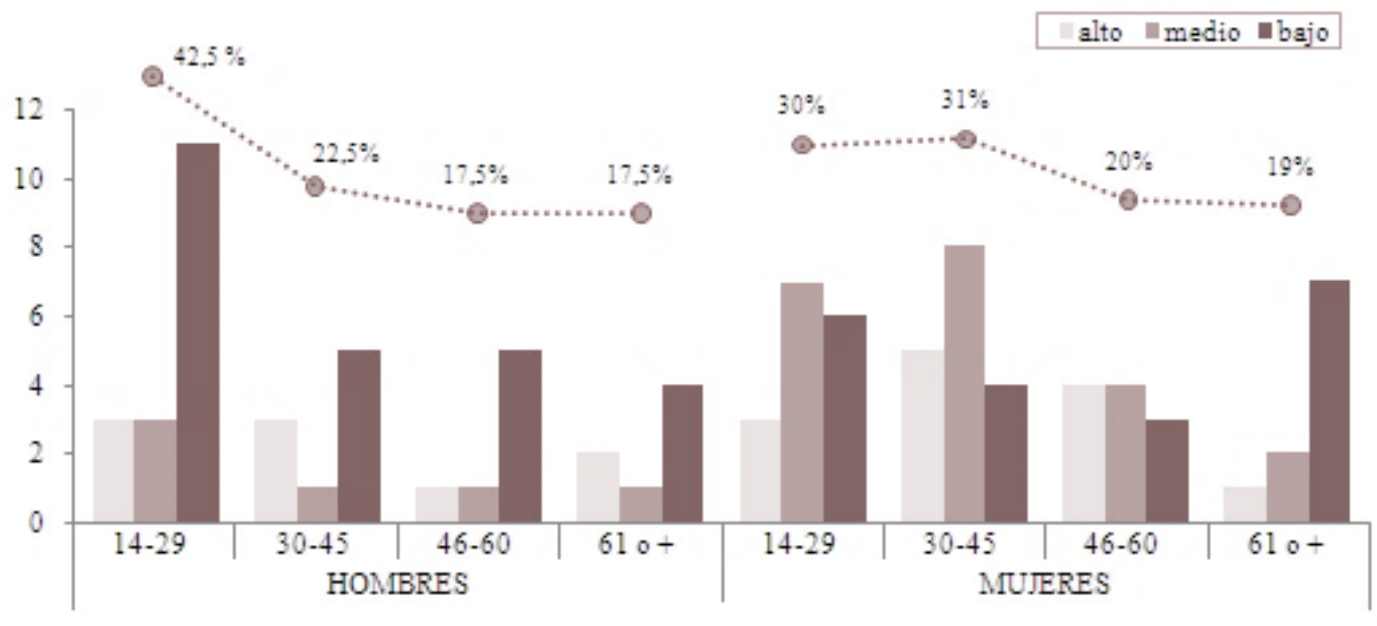

Fuente: Elaboración Propia

Los porcentajes expresados en las columnas muestran claramente la contribución de los hombres de clase baja al uso; mientras que la curva ubicada en la parte superior del diagrama 5 correspondiente a los porcentajes totales por grupo etario en ambos sexos, indica la disminución progresiva del uso ponderativo al aumentar la edad.

\section{Consideraciones finales}

El análisis realizado pone de manifiesto que el uso del posesivo posnominal se debe al efecto conjunto de variables lingüísticas y extralingüísticas. La relación semántica del sustantivo modificado es el predictor lingüístico que condiciona con más fuerza este uso en los tres dialectos. 
El resultado coincide con otros estudios, tanto en el habla de la variedad venezolana, como en la de otras ciudades americanas.

Con todo, la observación más relevante, desde mi punto de vista, tiene que ver con la naturaleza de los vínculos personales que expresan estas relaciones. Salvo en el caso de la relación filial, la preferencia de los hablantes a posponer la forma tónica aumenta cuando la entidad poseída expresa relaciones sociales no parentales.

De esta forma, resulta cuestionable la generalización de que el posesivo posnominal tiende a usarse con sustantivos que denotan relación de parentesco, ya que la preferencia de los hablantes a posponer la forma tónica disminuye cuando la entidad poseída expresa relaciones de consanguinidad ascendente. En virtud de que este tipo de sustantivos no denota una verdadera posesión, resulta válido suponer que el uso responde a la necesidad de enfatizar alguna otra inferencia asociada al vínculo personal.

El hablante está sujeto, consciente o inconscientemente, a la idea del bien común, del bienestar social orientado hacia el progreso de las personas, con lo cual, -y bajo la expectativa de una entrevista- no es de extrañar que trate de expresarse en términos de desarrollo personal y enfoque su expresividad en aquellas entidades más cercanas a la utilidad individual, marcando especialmente aquellas que expresan propósitos particulares (el anhelo mío) y autorrealización (el carro mío).

El uso del posesivo posnominal es, por lo tanto, una forma de con/rea-firmar, a través de la propiedad y la pertenencia, el posicionamiento social, bien de relaciones (tengo un núcleo conyugal, empleados, éxito amoroso), bien de una emocionalidad estable y de bienes. Cobra sentido, entonces, que quienes hagan mayor uso de este recurso expresivo sean los hablantes de clase social baja y los de mayor edad, ambos, sujetos a la presión de una sociedad en la cual el éxito se mide, generacionalmente, en térmico de posesiones, logros y contactos personales.

Aunque menos frecuentes, la función pragmática de los posesivos enfáticos también permite ponderar una característica reiterativa o inesperada y es un recurso expresivo productivo en el habla de los jóvenes, especialmente caraqueños de clase baja. 
En cuanto a la relevancia descriptiva de los constructos analíticos, en el presente estudio he utilizado el modelo de regresión lineal de efectos mixtos y los árboles de inferencia condicional, dos herramientas estadísticas poderosas que me han permitido elevar la verosimilitud del análisis y solventar las limitaciones propias del modelo tradicional en cuanto a la inclusión del hablante como fuente de variación. No obstante, el análisis de los usos menos abundantes, en su contexto discursivo, me permitió establecer premisas sobre las motivaciones de su empleo, útiles para futuros análisis.

Finalmente, vale la pena recordar que la muestra que aquí se analiza fue recogida para su estudio hace treinta años, de modo que una investigación similar en muestras de habla actual constituye una buena ocasión para confirmar estas tendencias.

\section{Referencias}

Aleza, M. (2010). Morfología y sintaxis. Observaciones gramaticales de interés en el español de América. Los posesivos. En M. Aleza \& J. M. Enguita (Coords.), La lengua española en América (p.138-144). Universitat de València: Valencia.

Barr, D., Levy, R., Scheepers, C. \& Tily, H. (2013). Random effects structure for confirmatory hypothesis testing: Keep it maximal. Journal of Memory and Language, 68, 255-278.

Bentivoglio, P. \& Sedano, M. (1992). Morfosintaxis. Cuadernos Lagoven. El idioma español de la Venezuela actual, 46-70.

Bentivoglio, P. \& Sedano, M. (1998). Viaje sintáctico de Catia a Petare. Revista Imagen, 31(1), 127-130.

Bentivoglio, P. (1996). La gramática del español hablado en Venezuela. Lengua y habla, 1(1), 21-39.

Bertolotti, V. (2014). Pronombres posesivos en el español rioplatense: Tres casos de reanálisis. Traslaciones, 1, 59-74.

Bouzouita, M., Castillo, M. \& Pato, E. (2018). Dialectos del español. Una nueva aplicación para conocer la variación actual y el cambio en las variedades del español. Dialectología, 20, 61-83.

De Stefano, L. \& Chumaceiro, I. (1992). Los posesivos de primera persona del singular y plural en el habla de Caracas. En E. Luna Traill (Coord.), Scripta Philologica. Homenaje a J. M. Lope Blanch (p.823839). México D.F.: UNAM. 
De Stefano, L. (1996). El adjetivo posesivo en el español hablado en Maracaibo. Iberoromania, 44, 39-51. Demonte, V. (2000). Gramática, variación y norma: una tipología. Revista Hispánica de Lingüística, 12, 349.

Eddington, D. (2017). Nominalized adverbs in Spanish: the intriguing case of detrás mío and its cohorts. Research in Corpus Linguistics, 5, 47-55.

Freeman, M. (2019). La expresión de la posesión nominal en Medellín, Colombia. Tesis de maestría. Baton Rouge: Louisiana State University.

Granda, G. (1966). La evolución del sistema de posesivos en el español atlántico. Estudio de morfología sincrónica. Boletín de la Real Academia Española, 46, 69-82.

Granda, G. (1997). Replanteamiento de un tema controvertido. Génesis y retención del doble posesivo en el español andino. Revista de Filología Española, 77, 139-147.

Guirado, K. (2009). (De)queísmo: uso deíctico y distribución social en el habla de Caracas. Caracas: CEP/FHE/UCV.

Guirado, K. (2012). Aquí se habla venezolano. Conversatorio: En defensa del español de Venezuela, Conferencia, Universidad Central de Venezuela.

Guirado, K. (2015). Reingeniería de Corpus en Venezuela: una propuesta metodológica para diversificar el análisis de los corpus del español hablado en Caracas, Letras, 92, 55-87.

Guirado, K. (2021). CORDIA-VEN-sXX: Un subcorpus dialectal para el estudio sociolingüístico del español hablado en Venezuela. Dialectología 26, 45-71.

Guy, G. (1988). Advanced VARBRUL análisis. En K. Ferrara, B. Brown, K. Walters \& J. Baughb (Eds.), Linguistic change and contact (p.124-136). Austin: University of Texas.

Johnson, D. (2009). Getting off the Goldvarb Standard: Introducing Rbrul for Mixed-Effects Variable Rule Analysis. Language and Linguistics Compass, 3(1), 359-383.

Lapesa, R. (1971). Sobre el artículo ante posesivo en castellano antiguo. En E. Coseriu \& W. Dieber Stemple (Eds.), Sprache und Geschichte. Festschrift für Harri Meir zum 65 (p.277-296). Munich: Wilhelm Fink Verlag.

Ledezma, M. de \& Barrera, L. (1985). Algunos fenómenos morfosintácticos del habla de Venezuela. Letras, 43, 139-222. 
Ledezma, M. de \& Obregón, H. (1990). Gramática del español de Venezuela. Caracas: IPC.

Lo Ponte, C. (2016). Análisis de la variación del español en Venezuela a través de video y grabaciones. Tesis de grado. Padua: Università degli Studi di Padova.

Marttinen, M. \& Bouzouita, M. (2018). Encima de mí vs. encima mío: un análisis variacionista de las construcciones adverbiales locativas con complementos preposicionales y posesivos en Twitter. Moderna språk, 112(1), 1-39.

Maslow, A. (1943). A Theory of Human Motivation. Psychological Review, 50, 370-396.

Murguey, A. (2010). El adverbio locativo descriptivo: sintaxis y semántica en el español venezolano, Letras, 52(81), 49-67.

Navarro, M. (2001). Los adverbios prepositivos en el habla de Valencia. Letras, 62,55-79.

Orozco, R. (2010). Variation in the expression of nominal possession in Costeño Spanish. Spanish in Context, 7(2), 194-220.

Pacheco, C. \& Bouzouita, M. (2017). El uso de los pronombres posesivos en el habla juvenil de La Habana: un análisis variacionista. En L. Ruiz, M. Álvarez \& A. Muñoz (Eds.), Nuevos Estudios sobre Comunicación Social (p.52-56). Santiago de Cuba: Centro de Lingüística Aplicada.

Paolillo, J. (2013). Individual effects in variation analysis: Model, software, and research design, Language Variation and Change, 25, 89-118.

Picallo, M. \& Rigau, G. (1999). El posesivo y las relaciones posesivas. En I. Bosque \& V. Demonte (Dirs.). Gramática Descriptiva de la Lengua Española (973-1023). Madrid: Espasa Calpe.

Pons, S. (2014). El siglo XX como diacronía: intuición y comprobación en el caso de o sea. RILCE, 30/3, 985-1016.

Porto-Dapena, J. (1982). Los posesivos personales del español: intento de descripción funcional. Dicenda, 1, 55-108.

Radelli, B. (1978). Los posesivos en español. Nueva Revista de Filología Hispánica, 27, 235-257.

RAE \& ASALE. (2005). Diccionario panhispánico de dudas. Madrid: Santillana.

RAE \& ASALE. (2009). Nueva gramática de la lengua española. Madrid: Espasa-Calpe. 
Salgado, Á. \& Bouzouita, M. (2017). El uso de las construcciones de adverbio locativo con pronombre posesivo en el español peninsular: un primer acercamiento diatópico. Zeitschrift für romanische Philologie, 133(3), 766-794.

Sánchez, C. (2008). Los determinantes posesivos en el español hablado costarricense. Filología y Lingüística XXXIV, 1, 193-208.

Santana, J. (2014). La estructura adverbio+posesivo en medios de comunicación digitales. Español Actual, 101, 7-30.

Satorre, F. (1999): Los posesivos en español. Valencia: Universitat de València.

Scrivner, O. \& Díaz-Campos, M. (2016), Language Variation Suite: A theoretical and methodological contribution for linguistic data analysis. Proceedings of the Linguistic Society of America, 1(29). $\begin{array}{lllllll}\text { Obtenido } & \text { el } & 14 & \text { de } & \text { mayo } & \text { de }\end{array}$ http://journals.linguisticsociety.org/proceedings/index.php/PLSA/article/view/3734.

Silva-Corvalán, C. \& Enrique-Arias, A. (2017). Sociolingüística y pragmática del español. Georgetown UP: Georgetown University Press.

Solkoff, K. (2002). Los pronombres de la subjetividad: primera y tercera persona en el contexto de la psicoterapia cognitiva. Subjetividad y procesos cognitivos, 2, 214-229.

Strobl, C., Malley, J. \& Tutz, G. (2009). An Introduction to Recursive Partitioning: Rationale, Application and Characteristics of Classification and Regression Trees, Bagging and Random Forests. Psychol Methods, 14(4), 323-348.

Tagliamonte, S. \& Baayen, H. (2012). Models, forests and trees of York English: Was/were variation as a case study for statistical practice, Language Variation and Change, 24, 135-178.

Ugueto, M. (2015). "Y me comí mis caraotas": Uso del posesivo átono en el español de Caracas. Sapiens, 16(1), 77-101. 